\title{
Improving the Performance of Fuzzy Minimum Spanning Tree based Routing Process through P- Node Fuzzy Multicasting Approach in MANET
}

\author{
Soham Bandyopadhyay \\ Dr.B.C.Roy Polytechnic, Durgapur, India \\ E-mail: sohamban@gmail.com \\ Sunil Karforma \\ The University of Burdwan, Burdwan, India \\ E-mail: sunilkarforma@yahoo.com
}

Received: 24 February 2018; Accepted: 18 April 2018; Published: 08 June 2018

\begin{abstract}
Mobile Ad-hoc Network (MANET) is mostly decentralized and self-adjustable network system. It is significant to optimize the overall network energy utilization and improve packet sending performance by reducing the errors, generated due to different real-life environmental effects. In this paper, considering atmospheric, environmental change and varying distance for topological change, we try to generate the routing cost. By introducing m-minimum (membership value as $\mathrm{m}$ ) triangular fuzzy number at interval based cost and energy of the network, we try to handle the uncertain environment. Here we generate both fuzzy minimum spanning tree (FMST) for a given n- nodes network and p-node fuzzy multicast minimum spanning tree (pFMMST), in fuzzy interval based format. Applying the fuzzy credibility distribution we modify the network routing cost and energy utilization for both FMST and pFMMST. Comparing the routing cost and residual energy for FMST and pFMMST of MANET, it is concluded that, pFMMST is better FMST based packet routing approach, with minimum routing cost, optimized total energy utilization and best possible technique to reduce the error which is generated due to the deviation of interval of upper and lower limit data in route cost and residual energy.
\end{abstract}

Index Terms-P-nodes fuzzy multicasting, spanning tree, routing, fuzzy credibility distribution, inverse credibility distribution, m-minimum triangular fuzzy number, standard deviation.

\section{INTRODUCTION}

A mobile ad-hoc network (MANET) is also known as wireless ad-hoc network. It is basically a continuous selfgenerating, particular infrastructure-less network of mobile devices, connected wirelessly without the support of a centralized administration.

According to different researches for transferring data from one node to another was explained previously, using most efficient multicasting techniques on MANETs. Location-aided routing in MANET was proposed through [3]. Chen et al. [1] analyzed the use of wireless and mobile technology in the education sector. WLAN optimization at the MAC and Network Levels was explained in [4]. Analyzing minimum cost multicast trees in ad hoc networks was explained in [5]. All these multicasting and broadcasting techniques on MANET [6, 22] with different routing algorithms[31] use crisp dataset and generate point estimated result, without considering real- life uncertain constraints. Here the fuzzy system is a most appropriate tool to deal with such uncertainties. Giving the priority to the fuzzy system, different researchers already used it in several mathematical applications. Minimum spanning tree problem by Zhou et al. [10] with fuzzy edge cost as a chance-constrained model was first formulated by [11]. Chang and Lee explained ranking index for fuzzy edge cost of spanning trees. Almeida et al. [13] proposed a genetic algorithm to derive fuzzy minimum spanning tree.

But the application area of the fuzzy system in wireless network routing field [8], is not very much extended. So in this paper, we try to incorporate fuzzy logic for reallife decision making to derive the routing cost and total energy utilization for transferring data packets from one digital device to another in MANET. But all these conclusive results do not point estimate. These are interval estimated. Using this fuzzy system we generate minimum spanning tree (Kruskal, Prims) and shortest path (Fuzzy Dijkstra techniques) [14,15].Through shortest path technique different multicast [2] groups of nodes transfer the data packets using less energy utilization as compared to data transfer scenario amongst all the nodes at minimum spanning tree structure. To do this we introduce m-minimum fuzzy triangular interval based estimation techniques. Fuzzy credibility distribution function with membership value $\mathrm{m}$ through [10] is used to generate the interval based cost between two nodes (mobile device) in graphical MANET structure. 
As we emphasis on real-life uncertain environment, so energy utilization value is also represented with interval estimation techniques with minimum and maximum energy limits. Here Heinzelman's energy model [23] is used to represent residual energy in the interval based format for transferring and receiving data packets. Using fuzzy shortest path technique we generate different fuzzy interval based p-nodes fuzzy multicast minimum spanning trees(pFMMST), where $\mathrm{p}$ is less than or equal to the total number of nodes(n) present in the graphical structure. As these multicast groups have less number of nodes, so topological changes or link failures have fewer effects on interval-based routing path cost and energy usage as compared to all the nodes(n) at minimum spanning tree of MANET graphical structure. Because the generated route cost and energy both are interval based, so errors due to deviation in between upper and lower limit value often generate the imperfection in optimization. Here the possibility of such type of errors also can be reduced by introducing pFMMST in place of normal FMST approach. Considering all these possible real lives constrains as uncertainty we try to improve the FMST based routing path cost, energy utilization and reduce the interval based data deviation related errors for MANET through the optimized method of the mminimum fuzzy triangular interval based value of pFMMST.

To analyze the overall details we organize the rest of the paper in the following way: In section 2, the mathematical models are generated to simulate our dataset. In Section 3, we explain the fuzzy shortest path approach in p-node fuzzy multicasting minimum spanning tree and discuss the improvement of routing cost, energy utilization of nodes and possibility of errors due to interval based upper and lower limit data deviation, at FMST through pFMMST approach. Through Section 4 , an example MANET network structure is taken to generate simulation techniques using fuzzy mathematical modeling. Where different tables and graphical representations are produced to show the improvement of routing cost, energy utilization and probable errors for interval-based route cost and energy deviation in pFMMST as compare to FMST. Finally, at section 5, we conclude and generate an idea for further future improvement.

\section{MAthematical Modeling}

Here a network structure is considered, with n nodes, which communicate amongst them using the wireless link. Considering our assumption if we take $n$ node minimum spanning tree and any packet is forwarded by a node, it should be accepted by all its neighbors. It is believed that while configuring a multicast network, the source node will send the packets to its multicast group members only where the other neighbor nodes, which are not the member of that multicast group, will not receive a single packet. Which supports the packets to move less routing path cost and the packet transferring energy utilization will also reduce. Here the concepts of m-minimum triangular fuzzy variables and credibility distributed fuzzy variables are introduced. These are used for the route cost and energy utilization to transmit packets between two neighbor nodes.

Few significant definitions, related to our discussion, as follows.

\section{A. Triangular Fuzzy number}

A Triangular fuzzy number $\tilde{A}=\left\{a_{1}, a_{2}, a_{3}\right\}$ is interpreted with the membership functions and holds the below following conditions.

1. From $a_{1}$ to $a_{2}$ the membership value gets increased.

2. From $a_{2}$ to $a_{3}$ the membership value gets decreased.

3. $a_{1} \leq a_{2} \leq a_{3}$

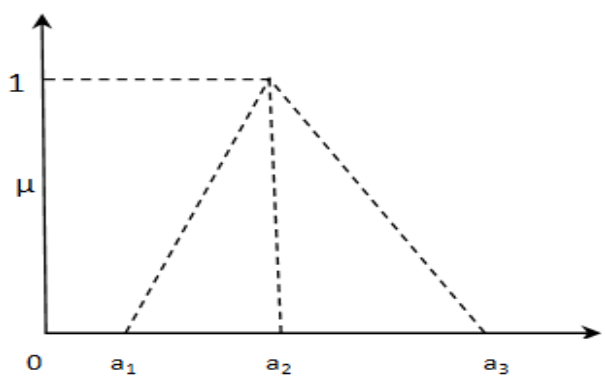

Fig.1. Triangular Fuzzy Number

Suppose for a value $x$, the membership function is $\mu_{\tilde{A}}(x)$, where $0 \leq \mu_{\tilde{A}}(x) \leq 1$

According to Fig. 1 it can be defined as

$$
\mu_{\tilde{A}}(x)=\left\{\begin{aligned}
0 & \text { if } x<a_{1} \\
\frac{x-a_{1}}{a_{2}-a_{1}} & \text { if } a_{1} \leq x \leq a_{2} \\
\frac{a_{2}-x}{a_{3}-a_{2}} & \text { if } a_{2}<x \leq a_{3} \\
1 & \text { if } x>a_{3}
\end{aligned}\right\}
$$

\section{B. Credibility Distribution of Fuzzy Variable}

The credibility distribution $\beta: \psi \rightarrow[0,1]$ of a fuzzy variable $\Phi$ is defined as (Zhou et al., 2015)

$$
\beta(x)=\operatorname{Cr}\{\lambda \in \theta \mid \Phi(\lambda) \leq x\}
$$

Where

$\operatorname{Cr}\{\Phi \leq r\}=\frac{1}{2}\left(\sup _{\mathrm{x} \leq \mathrm{r}} \mu(\mathrm{x})+1-\sup _{\mathrm{x}>\mathrm{r}} \mu(\mathrm{x})\right)$

Here $\mu$ is membership value and $r$ is a real value. Where $0 \leq \mu \leq 1$

Applying equation (2) and equation (3) at equation (1) we get

$$
\begin{gathered}
\beta(x)=\operatorname{Cr}\{\Phi \leq x\}= \\
0 \quad \text { if } x<a_{1} \\
\left\{\begin{array}{cl}
\frac{x-a_{1}}{2\left(a_{2}-a_{1}\right)} & \text { if } a_{1}<x \leq a_{2} \\
\frac{x+a_{3}-2 a_{2}}{2\left(a_{3}-a_{2}\right)} & \text { if } a_{2}<x \leq a_{3} \\
1 & \text { if } x>a_{3}
\end{array}\right\}
\end{gathered}
$$


From this credibility distribution, we get inverse credibility distribution values, which are basically interval, estimated fuzzy values with lower and upper bound limit.

$$
\left.\begin{array}{c}
\beta^{-1}(m)= \\
a_{1}+2\left(a_{2}-a_{1}\right) m \text { if } 0 \leq m \leq 0.5 \\
2 a_{2}-a_{3}+2\left(a_{3}-a_{2}\right) m \text { if } 0.5<m \leq 1
\end{array}\right\}
$$

\section{Fuzzy Weighted Graph}

A normal weighted graph is a collection of vertices and edges with specific weights.

$$
\text { So, } G=(V, E, W)
$$

Where

$$
\begin{gathered}
V=\left\{v_{2}, v_{2}, \ldots, v_{n}\right\} \\
E=\left\{e_{1}, e_{2}, \ldots, e_{k}\right\}, W=\left\{w_{1}, w_{2}, \ldots, w_{k}\right\}
\end{gathered}
$$

Here total number of vertices, edges and weights are n, $\mathrm{k}$, $\mathrm{k}$ respectively.

If $k=\frac{n(n-1)}{2}, \mathrm{t}$ he graph will be complete weighted graph.

In a fuzzy weighted graph, the cost or weight of the edges between two nodes will be fuzzy.

Here, we consider m-minimum triangular fuzzy data to represent the cost.

So, for fuzzy weighted graph

$$
\tilde{G}=(V, E, \widetilde{W})
$$

Where,

$$
\begin{gathered}
V=\left\{v_{2}, v_{2}, \ldots, v_{n}\right\} \\
E=\left\{e_{1}, e_{2}, \ldots, e_{k}\right\}, \widetilde{W}=\left\{\widetilde{w}_{1}, \widetilde{w}_{2}, \ldots, \widetilde{w}_{k}\right\} \\
\widetilde{w}_{i}=\left\{a_{1}^{i}, a_{2}^{i}, a_{3}^{i}\right\}
\end{gathered}
$$

This is basically a triangular fuzzy number. It means, here we take the cost or weight of the edge $e_{i}$ as fuzzy data. Using credibility distribution equation (4) on $\widetilde{w}_{i}$ we get

$$
\begin{aligned}
& \beta_{i}(x)=\operatorname{Cr}\left\{\Phi_{i} \leq x\right\}= \\
& \left\{\begin{array}{c}
0 \quad \text { if } x \leq a_{1}^{i} \\
\frac{x-a_{1}^{i}}{2\left(a_{2}^{i}-a_{1}^{i}\right)} \quad \text { if } a_{1}^{i}<x \leq a_{2}^{i} \\
\frac{x+a_{3}^{i}-2 a_{2}^{i}}{2\left(a_{3}^{i}-a_{2}^{i}\right)} \quad \text { if } a_{2}^{i}<x \leq a_{3}^{i} \\
1 \text { if } x>a_{3}^{i}
\end{array}\right\}
\end{aligned}
$$

Now applying inverse credibility distribution equation (5), we can get the cost $\widetilde{w}_{1}$ of edge $e_{i}$ as interval estimated manner.

Where

$$
\begin{gathered}
\widetilde{w}_{i}=\left[a_{1}^{i}+2\left(a_{2}^{i}-a_{1}^{i}\right) m, 2 a_{2}^{i}-a_{3}^{i}+2\left(a_{3}^{i}-a_{2}^{i}\right) m\right] \\
0 \leq m \leq 1
\end{gathered}
$$

Which is m-minimum interval based fuzzy data with lower and upper limit.

Now using Mean-max technique we can defuzzify all the interval values into crisp data and get the best possible path cost of total $\mathrm{n}$ nodes.

$$
\widetilde{w}_{i}=\left[\frac{a_{1}^{i}+2\left(a_{2}^{i}-a_{1}^{i}\right) m+2 a_{2}^{i}-a_{3}^{i}+2\left(a_{3}^{i}-a_{2}^{i}\right) m}{2}\right]
$$

\section{Fuzzy Residual Energy}

Here we have used Heinzelman's energy model for transmitting packets from one router to another router.

While transferring packets in between two nodes, at the sender side, the energy is required to transmit the packet and at receiver side energy is required to receive the packet.

Suppose, $k$ bit data is transmitted and distance between two nodes is $d$ (Here distance unit is considered as meter), according to Heinzelman's energy model Energy consumption for transmitting packet is given as

$$
E_{T}(k, d)=E_{\text {elec }} \cdot k+E_{a m p} \cdot k \cdot d^{2}
$$

Energy consumption for receiving packet is given as

$$
E_{R}(k)=E_{\text {elec }} \cdot k
$$

Where

$$
E_{\text {elec }}=50 \mathrm{~nJ} / \mathrm{bit}, E_{\text {amp }}=\frac{100 \mathrm{pJ}}{\text { bit }} / \mathrm{m}^{2}
$$

Now for interval based route cost from equation (7) 1

$$
\begin{gathered}
\tilde{\mathrm{d}}_{\mathrm{i}}=\left[\mathrm{a}_{1}^{\mathrm{i}}+2\left(\mathrm{a}_{2}^{\mathrm{i}}-\mathrm{a}_{1}^{\mathrm{i}}\right) \mathrm{m}, 2 \mathrm{a}_{2}^{\mathrm{i}}-\mathrm{a}_{3}^{\mathrm{i}}+2\left(\mathrm{a}_{3}^{\mathrm{i}}-\mathrm{a}_{2}^{\mathrm{i}}\right) \mathrm{m}\right] \\
0 \leq \mathrm{m} \leq 1 \\
\tilde{d}_{i}=\left[d_{1}^{i}, d_{2}^{i}\right]
\end{gathered}
$$

So, fuzzy transmission energy,

$$
\tilde{E}_{T}^{i}\left(k, \tilde{d}^{i}\right)=\left[\tilde{E}_{T}^{i}\left(k, \tilde{d}_{1}^{i}\right), \tilde{E}_{T}^{i}\left(k, \tilde{d}_{2}^{i}\right)\right]
$$

Where

$$
\begin{aligned}
& \tilde{E}_{T}^{i}\left(k, \tilde{d}_{1}^{i}\right)=E_{\text {elec }} \cdot k+E_{\text {amp }} \cdot k \cdot \tilde{d}_{1}^{i^{2}} \\
& \tilde{E}_{T}^{i}\left(k, \tilde{d}_{2}^{i}\right)=E_{\text {elec }} \cdot k+E_{\text {amp }} \cdot k \cdot \tilde{d}_{2}^{i^{2}}
\end{aligned}
$$

Fuzzy receiving energy

$$
\tilde{E}_{R}^{i}(k)=E_{\text {elec }} \cdot k
$$

Total residual energy consumption for transmitting one packet is

$$
\tilde{E}_{R}^{i}=\left[\tilde{E}_{R}^{i^{L}}, \tilde{E}_{R}^{i^{H}}\right]
$$


$\tilde{E}_{R}^{i}=\left[\tilde{E}_{T}^{i}\left(k, \tilde{d}_{1}^{i}\right)+\tilde{E}_{R}^{i}(k), \tilde{E}_{T}^{i}\left(k, \tilde{d}_{2}^{i}\right)+\tilde{E}_{R}^{i}(k)\right]$

Where

$$
\begin{aligned}
& \tilde{E}_{R}^{i^{L}}=\tilde{E}_{T}^{i}\left(k, \tilde{d}_{1}^{i}\right)+\tilde{E}_{R}^{i}(k) \\
& \widetilde{E}_{R}^{i^{H}}=\tilde{E}_{T}^{i}\left(k, \tilde{d}_{2}^{i}\right)+\tilde{E}_{R}^{i}(k)
\end{aligned}
$$

After defuzzification

$$
\tilde{E}_{R}^{c^{i}}=\left[\frac{\tilde{E}_{R}^{L}+\tilde{E}_{R}^{H}}{2}\right]
$$

\section{E. Deviation of Upper and Lower Limit Fuzzy Value}

For $e_{i}$ edge the route cost is $\widetilde{w}_{i}$ from equation (7) and (8) we get

$$
\begin{gathered}
\widetilde{w}_{i}=\left[a_{1}^{i}+2\left(a_{2}^{i}-a_{1}^{i}\right) m, 2 a_{2}^{i}-a_{3}^{i}+2\left(a_{3}^{i}-\right.\right. \\
\left.\left.a_{2}^{i}\right) m\right] ; 0 \leq m \leq 1 \\
=\left[\widetilde{w}_{i}^{1}, \widetilde{w}_{i}^{2}\right]
\end{gathered}
$$

So, the deviation for lower and upper limit route cost is

$$
s d\left(\widetilde{w}_{i}\right)=\sqrt{\left[\frac{\left(\widetilde{w}_{i}^{1}-w_{i}^{c}\right)^{2}+\left(\widetilde{w}_{i}^{2}-w_{i}^{c}\right)^{2}}{2}\right]}
$$

Where

$$
w_{i}^{c}=\left[\frac{\widetilde{w}_{i}^{1}+\widetilde{w}_{i}^{2}}{2}\right]
$$

Using equation (14) and (15) we get deviation for lower and upper limit of residual energy

$$
s d\left(E_{R}^{i}\right)=\sqrt{\left[\frac{\left(\tilde{E}_{R}^{L}-\tilde{E}_{R}^{i}\right)^{2}+\left(\tilde{E}_{R}^{i H}-\tilde{E}_{R}^{i}\right)^{2}}{2}\right]}
$$

\section{F. Fuzzy Minimum Spanning Tree}

Considering fuzzy weighted graph we know,

$$
\tilde{G}=(V, E, \widetilde{W})
$$

Where

$$
\begin{gathered}
V=\left\{v_{2}, v_{2}, \ldots, v_{n}\right\} \\
E=\left\{e_{1}, e_{2}, \ldots, e_{k}\right\}, \widetilde{W}=\left\{\widetilde{w}_{1}, \widetilde{w}_{2}, \ldots, \widetilde{w}_{k}\right\} \\
\widetilde{w}_{i}=\left\{a_{1}^{i}, a_{2}^{i}, a_{3}^{i}\right\}
\end{gathered}
$$

A fuzzy spanning tree $T=(V, \widetilde{S})$ of $\tilde{G}=(V, E, \widetilde{W})$ is a connected acyclic sub graph, containing all vertices, where $\mathrm{S}$ is the set of edges, contained in T. So, $\tilde{S} \subseteq E$

The weight of a spanning tree $\mathrm{T}$ can be formulated as

$$
W(T, \widetilde{w})=\sum_{e_{i} \in T} \widetilde{w}_{i}
$$

Here according to equation (7)

$$
\begin{gathered}
\widetilde{w}_{i}=\left[a_{1}^{i}+2\left(a_{2}^{i}-a_{1}^{i}\right) m, 2 a_{2}^{i}-a_{3}^{i}+2\left(a_{3}^{i}-\right.\right. \\
\left.\left.a_{2}^{i}\right) m\right] ; 0 \leq m \leq 1
\end{gathered}
$$

Now using Mean-max technique we can defuzzify all the interval values into crisp data and get the best possible weight.

For a given $\operatorname{graph} \tilde{G}=(V, E, \widetilde{W})$, a spanning tree $T^{0}$ is called FMST

When,

$$
W\left(T^{0}, \widetilde{w}\right) \leq W(T, \widetilde{w})
$$

Where

$$
\mathrm{W}\left(\mathrm{T}^{0}, \widetilde{\mathrm{W}}\right)=\left[\mathrm{W}\left(\mathrm{T}^{0}, \widetilde{\mathrm{W}}^{\mathrm{L}}\right), \mathrm{W}\left(\mathrm{T}^{0}, \widetilde{\mathrm{W}}^{\mathrm{H}}\right)\right]
$$

\section{G. Fuzzy Dijkstra Shortest Path}

Famous Dutch scientist Edsger Dijkstra established the Dijkstra algorithm in the year of 1956 and officially published in 1959. Here Dijkstra's algorithm is used generate the shortest route between any two nodes (Digital device) in MANET network structure.

\section{Conventional Dijkstra shortest path algorithm}

Dijkstra_shortestpath ( $v$, cost, distance, $n$ )

// for $1 \leq i \leq n$ distance[i] represents the shortest path distance from node $v$ to $i$

f

for $j:=1$ to $n$ do

l

I/initialize $S$.

$S[v]:=$ false; distance $[j]:=\operatorname{cost}[v, j] ;$

\}

$S[v]:=$ true; distance $[v]:=0.0 ;$ //insert $v$ in $S$. for $m:=2$ to $n$ do

\{

// determine $n-1$ path from $v$.

// choose $u$ from those sets of nodes which are unavailable at $S$ and distance [u] will be minimum.

$S[u]:=$ true; // put $u$ in $S$.

for (each $p$ adjacent to $u$ with $S[p]=$ false) do //Update distances.

if (distance $[p]>$ distance $[u]+\operatorname{cost}[u, p]))$ then $\operatorname{distance}[p]:=\operatorname{distance}[u]+\operatorname{cost}[u, p]$;

\}

\}

\section{Fuzzy Dijkstra shortest path algorithm}

As we are working on fuzzy environment, according to conventional Dijkstra algorithm usable crisp point estimated path cost is changed to interval based path cost. For processing Dijkstra algorithm we use the following steps.

1. At first, we use inverse credibility on m-minimum 
triangular fuzzy path cost of the network and generate all the path cost as interval based fuzzy number.

2. Here each cost of network path has two values. One is upper bound and another is lower bound.

3. Using the upper bound value and lower bound value we generate the shortest path for each pair of nodes.

Suppose using Dijkstra algorithm on upper bound and lower bound values, we get the shortest paths of $\left(v_{i}, v_{j}\right)$ are $l_{1}$ and $l_{2}$ respectively.

4. Now the shortest path of $\left(v_{i}, v_{j}\right)$ is considered as $\left[l_{1}, l_{2}\right]$ Using the middle of maxima method according to equation (8), we can defuzzify this interval based value as $l$, where $l=l_{1}+l_{2} / 2$ is minimum shortest path cost between $\left(v_{i}, v_{j}\right)$

\section{P-Node FuZzy Multicasting Minimum SPANNing TREE}

For fuzzy weighted graph $\tilde{G}=(V, E, \widetilde{W})$

Where,

$$
\begin{gathered}
V=\left\{v_{2}, v_{2}, \ldots, v_{n}\right\} \\
E=\left\{e_{1}, e_{2}, \ldots, e_{k}\right\}, \widetilde{W}=\left\{\widetilde{w}_{1}, \widetilde{w}_{2}, \ldots, \widetilde{w}_{k}\right\} \\
\widetilde{w}_{i}=\left\{a_{1}^{i}, a_{2}^{i}, a_{3}^{i}\right\}
\end{gathered}
$$

This is basically triangular fuzzy number. It means, here we take the cost or weight of the edge $e_{i}$ as fuzzy data.

Using fuzzy Dijkstra shortest path technique, we can generate all pair shortest paths.

Suppose,

$$
\begin{gathered}
\operatorname{Spath}\left(v_{i}, v_{j}\right) \\
v_{i} \rightarrow v_{r} \rightarrow v_{q} \ldots v_{s} \rightarrow v_{j}
\end{gathered}
$$

Where, the number of nodes is $\mathrm{p}$.

Where $\operatorname{Spath}\left(v_{i}, v_{j}\right)$, signifies the shortest route between two nodes $\left(v_{i}, v_{j}\right)$ and $p \leq n_{s}$

$n_{s}=$ number of nodes in FMST for a particular source and destination.

So, the total path cost is.

$$
\begin{aligned}
\sum_{l=1}^{P} \widetilde{w}_{i}= & {\left[\sum_{l=1}^{p} a_{1}^{l}+2\left(a_{2}^{l}-a_{1}^{l}\right) m, \sum_{i=1}^{p} 2 a_{2}^{l}-a_{3}^{l}+\right.} \\
& \left.2\left(a_{3}^{l}-a_{2}^{l}\right) m\right]
\end{aligned}
$$

Now using Mean-max technique we can defuzzify all the interval values into crisp data and get the best possible cost of total $\mathrm{p}$ nodes

$\sum_{l=1}^{P} \widetilde{W}_{i}=\left[\frac{\sum_{l=1}^{p} a_{1}^{l}+2\left(a_{2}^{l}-a_{1}^{l}\right) m+\sum_{l=1}^{p} 2 a_{2}^{l}-a_{3}^{l}+2\left(a_{3}^{l}-a_{2}^{l}\right) m}{2}\right]$

Where $v_{i} \rightarrow v_{r}, v_{r} \rightarrow v_{q}$ up to $v_{s} \rightarrow v_{j}$ the minimum weights are $\left\{\widetilde{w}_{1}, \widetilde{w}_{2}, \ldots, \widetilde{w}_{p}\right\}$ respectively.
Statement 1. If for any MANET network total number of active nodes(digital device) are $n$ to route the packets, the total number of multicasting groups(act as separate network structure for transferring packet) with two or more active nodes will be, $2^{n}-(1+n)$

Explanation: According to the set theory we can say, Cardinality of $V=n$ So, the power set for $\mathrm{V}$ is $P|V|$, where all possible subsets of nodes are included.

Now, $P|V|=2^{n}$ where there is a null subset and $n$ number of single node subsets.

For creating multicasting group we can omit $(1+n)$ number of subsets.

So, the number of subsets of nodes with at least 2 or more nodes will be $2^{n}-(1+n)$.

Here we are interested to create multicast group MANET, each with at least 3 nodes. So number of multicast groups will be $2^{n}-\left(1+n+n_{C_{2}}\right)$.

Statement 2. The network routing path cost of pFMMST is less than or equal to FMST of $\widetilde{G}$ for a particular source and destination node.

Explanation: As, $p \leq n_{S}$ from equation (19) we get

$$
\sum_{\mathrm{i}=1}^{\mathrm{p}} \widetilde{\mathrm{w}}_{\mathrm{i}} \leq \mathrm{W}_{\mathrm{n}_{\mathrm{S}}}\left(\mathrm{T}^{0}, \widetilde{\mathrm{w}}\right)
$$

it means that, routing path cost of pFMMST is less than FMST. For other pFMMSTs' also equation (15) will get satisfied.

Statement 3. The network residual energy for routing the packets through pFMMST is less than or equal to the network residual energy of the FMST of $\tilde{\boldsymbol{G}}$

Explanation: Total fuzzy residual energy utilization in FMST can be calculated from equation (14) and (15) as

$$
\sum_{i=1}^{n_{S}} \tilde{E}_{R}^{i}=\left[\sum_{i=1}^{n_{S}} \tilde{E}_{R}^{i^{L}}, \sum_{i=1}^{n_{S}} \tilde{E}_{R}^{i^{H}}\right]
$$

Again using the same procedure and equations (14), (15) the total residual energy for pFMMSTs will be

$$
\sum_{l=1}^{p} \tilde{E}_{R}^{l}=\left[\sum_{l=1}^{p} \tilde{E}_{R}^{l}{ }^{L}, \sum_{l=1}^{p} \tilde{E}_{R}^{l}{ }^{H}\right]
$$

As, $p \leq n_{s}$

$$
\sum_{l=1}^{p} \tilde{E}_{R}^{l} \leq \sum_{i=1}^{n_{S}} \tilde{E}_{R}^{i}
$$

Which signifies that, total fuzzy residual energy utilization in pFMMST is less than or equal to FMST.

Comparison of p-node multicast minimum spanning tree and minimum spanning tree is one of the significant areas to increase the performance of MANETs. But in real life uncertain environment, it is found that point estimated result analysis in the crisp environment does not generate satisfactory results because different physical constrains in MANET structure create the variation, which does not generate any optimum decision oriented result. So the interval estimated fuzzy system is applied to improve the quality of decision making. 
Statement 4. The deviation of upper and lower limit value in interval based total route cost in pFMMST is less or equal to FMST.

Explanation:

$$
\sum_{l=1}^{p} \widetilde{w}_{l}=\left[\sum_{l=1}^{p} \widetilde{w}_{l}^{L}, \sum_{l=1}^{p} \widetilde{w}_{l}^{H}\right]
$$

According to equation (16)

$$
\frac{s d\left(\sum_{l=1}^{p} \widetilde{w}_{l}\right)=}{\sqrt{\left[\frac{\left.\left(\sum_{l=1}^{p} \widetilde{w}_{l}^{L}-\sum_{l=1}^{p} w_{l}^{c}\right)^{2}+\left(\sum_{l=1}^{p} \widetilde{w}_{l}^{H}-\sum_{l=1}^{p} w_{l}^{c}\right)^{2}\right]}{2}\right]}}
$$

From equation (19)

$$
\sqrt{\frac{s d\left(W\left(T^{0}, \widetilde{w}\right)\right)=}{\sqrt{\frac{\left(W\left(T^{0}, \widetilde{w}^{L}\right)-W\left(T^{0}, \widetilde{w}^{c}\right)\right)^{2}+\left(W\left(T^{0}, \widetilde{w}^{H}\right)-W\left(T^{0}, \widetilde{w}^{c}\right)\right)^{2}}{2}}}}
$$

Where

$$
W\left(T^{0}, \widetilde{W}^{c}\right)=\left[\frac{W\left(T^{0}, \widetilde{w}^{L}\right)+W\left(T^{0}, \widetilde{w}^{H}\right)}{2}\right]
$$

As $\sum_{l=1}^{p} \widetilde{w_{l}} \leq W\left(T^{0}, \widetilde{w}^{c}\right)$

So from equation (24) and (25) it can be concluded

$$
\left(T^{0}, \widetilde{w}\right) \geq s d\left(\sum_{l=1}^{p} \widetilde{w}_{l}\right)
$$

Statement 5. The deviation of upper and lower limit value in the interval based total residual energy for most of the pair of nodes in pFMMST, is less or equal to FMST.

Explanation: According to equation (17), we get

$$
\begin{aligned}
& \sqrt{\frac{s d\left(\sum_{l=1}^{p} \tilde{E}_{R}^{l}\right)=}{\frac{\left(\sum_{l=1}^{p} \tilde{E}_{R}^{L}-\sum_{l=1}^{p} \tilde{E}_{R}^{c}\right)^{2}+\left(\sum_{l=1}^{p} \tilde{E}_{R}^{l}-\sum_{l=1}^{p} \tilde{E}_{R}^{c}\right)^{2}}{2}}}
\end{aligned}
$$

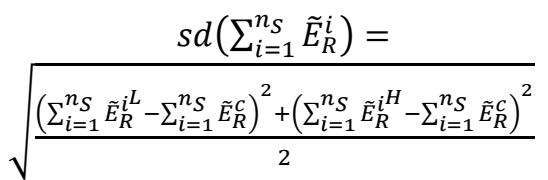

As $\sum_{l=1}^{p} \tilde{E}_{R}^{l} \leq \sum_{i=1}^{n_{S}} \tilde{E}_{R}^{i}$

For $p \leq n_{s}$ so from equation (29), (30) it can be depicted that for most of the pair of nodes

$$
s d\left(\sum_{l=1}^{p} \tilde{E}_{R}^{l}\right) \leq s d\left(\sum_{i=1}^{n_{S}} \tilde{E}_{R}^{i}\right)
$$

On the other hand, for very few pair of nodes the following exception may occur:

$$
\begin{aligned}
& \left(\sum_{l=1}^{p} \tilde{E}_{R}^{l^{L}}-\sum_{l=1}^{p} \tilde{E}_{R}^{c}\right)^{2}+\left(\sum_{l=1}^{p} \tilde{E}_{R}^{l^{H}}-\sum_{l=1}^{p} \tilde{E}_{R}^{c}\right)^{2} \\
\geq & \left(\sum_{i=1}^{n_{S}} \tilde{E}_{R}^{i^{L}}-\sum_{i=1}^{n_{S}} \tilde{E}_{R}^{c}\right)^{2}+\left(\sum_{i=1}^{n_{S}} \tilde{E}_{R}^{i^{H}}-\sum_{i=1}^{n_{S}} \tilde{E}_{R}^{c}\right)^{2}
\end{aligned}
$$

But the possibility of above condition (as per equation (32)), is exceptionally rare where the error rate for the imprecise residual energy of pFMMST is greater than FMST.

According to the normal statistical convention, with the increase of standard deviation, the error is also increased. Here the interval based imprecise data is considered, where the deviation of upper and lower limit value should be justified to generate an optimized result.

Here from equation (28) and (31), it is shown that pFMMST gives much more optimized deviation of interval based route cost and residual energy utilization(for most of the pair of nodes) than FMST. In it pFMMST gives lower or equal value standard deviation, compared to FMST, for route cost and energy usage.

\section{SimUlation STUDY AND RESUlt ANALYSIS}

In order to study the path distance and packet sending energy optimization in a MANET, we generate FMST and pFMMST from a fuzzy weighted graph. Here the path distance and residual energy are considered with meter and nano joule as unit respectively. We use Maple12, Math Type 6 and Microsoft Office Excel 2007 as simulators to design the fuzzy graph through which we calculate all pairs of the fuzzy minimum shortest path using Dijkstra algorithm and FMST, using Kruskal algorithm.

Table 1. Weight Details of the Fuzzy Graph

\begin{tabular}{|l|l|l|l|}
\hline $\begin{array}{l}\text { Edge } \\
\left(v_{i}, v_{j}\right)\end{array}$ & $\begin{array}{l}\text { Fuzzy Weight } \\
\widetilde{w}_{i} \\
=\left\{a_{1}^{i}, a_{2}^{i}, a_{3}^{i}\right\}\end{array}$ & $\begin{array}{l}\text { Inverse credibility } \\
\beta^{-1}(m)\end{array}$ & $\begin{array}{l}\boldsymbol{\beta}^{-1}(m) \text { With } \\
\mathrm{m}=0.8\end{array}$ \\
\hline$(1,2)$ & $(2,4,7)$ & {$[2+4 \mathrm{~m}, 1+6 \mathrm{~m}]$} & {$[5.2,5.8]$} \\
\hline$(2,3)$ & $(3,4,5)$ & {$[3+2 \mathrm{~m}, 3+2 \mathrm{~m}]$} & {$[4.6,4.6]$} \\
\hline$(3,4)$ & $(3,4,6)$ & {$[3+2 \mathrm{~m}, 2+4 \mathrm{~m}]$} & {$[4.6,5.2]$} \\
\hline$(4,7)$ & $(2,3,5)$ & {$[2+2 \mathrm{~m}, 1+4 \mathrm{~m}]$} & {$[3.6,4.2]$} \\
\hline$(6,7)$ & $(2,4,6)$ & {$[2+2 \mathrm{~m}, 1+4 \mathrm{~m}]$} & {$[3.6,4.2]$} \\
\hline$(5,6)$ & $(2,3,4)$ & {$[2+2 \mathrm{~m}, 2+2 \mathrm{~m}]$} & {$[3.6,3.6]$} \\
\hline$(5,8)$ & $(2,3,5)$ & {$[2+2 \mathrm{~m}, 1+4 \mathrm{~m}]$} & {$[3.6,4.2]$} \\
\hline$(8,9)$ & $(3,4,6)$ & {$[3+2 \mathrm{~m}, 2+4 \mathrm{~m}]$} & {$[4.6,5.2]$} \\
\hline$(9,11)$ & $(4,5,7)$ & {$[4+2 \mathrm{~m}, 3+4 \mathrm{~m}]$} & {$[5.6,6.2]$} \\
\hline$(10,11)$ & $(2,3,5)$ & {$[2+2 \mathrm{~m}, 1+4 \mathrm{~m}]$} & {$[3.6,4.2]$} \\
\hline$(8,10)$ & $(8,9,10)$ & {$[8+2 \mathrm{~m}, 8+2 \mathrm{~m}]$} & {$[9.6,9.6]$} \\
\hline$(6,8)$ & $(5,7,10)$ & {$[5+4 \mathrm{~m}, 4+6 \mathrm{~m}]$} & {$[8.2,8.8]$} \\
\hline$(5,10)$ & $(14,17,19)$ & {$[14+6 \mathrm{~m}, 15+4 \mathrm{~m}]$} & {$[18.8,18.2]$} \\
\hline$(2,5)$ & $(15,17,20)$ & {$[15+4 \mathrm{~m}, 14+6 \mathrm{~m}$} & {$[18.2,18.8]$} \\
\hline$(7,9)$ & $(12,13,14)$ & {$[12+2 \mathrm{~m}, 12+2 \mathrm{~m}]$} & {$[13.6,13.6]$} \\
\hline$(3,6)$ & $(8,10,13)$ & {$[8+4 \mathrm{~m}, 7+6 \mathrm{~m}]$} & {$[11.2,11.8]$} \\
\hline$(1,4)$ & $(10,13,17)$ & {$[10+6 \mathrm{~m}, 9+8 \mathrm{~m}]$} & {$[14.8,15.4]$} \\
\hline$(1,3)$ & $(6,9,11)$ & {$[6+6 \mathrm{~m}, 7+4 \mathrm{~m}]$} & {$[10.8,10.2]$} \\
\hline
\end{tabular}

From Fig.2, we generate the FMST and calculate the interval based fuzzy weight $W_{n_{S}}\left(T^{0}, \widetilde{w}\right)$ of the acyclic tree, given in Table 2 . 


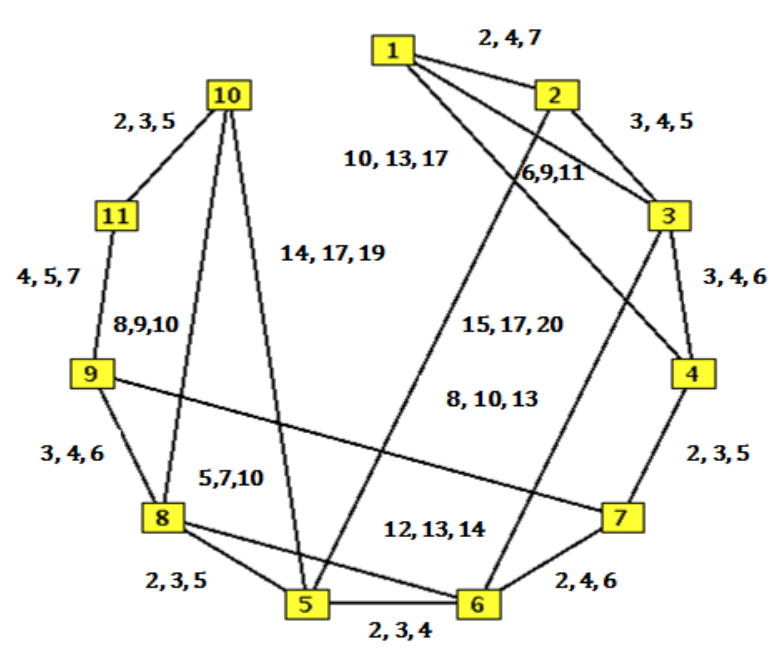

Fig.2. Fuzzy Graph (MANET structure)

Table 2. Weight Details of FMST

\begin{tabular}{|l|l|l|l|}
\hline $\begin{array}{l}\text { Edge } \\
\left(v_{i}, v_{j}\right)\end{array}$ & $\begin{array}{l}\text { Fuzzy Weight } \\
\widetilde{w}_{i}=\left\{a_{1}^{i}, a_{2}^{i}, a_{3}^{i}\right\}\end{array}$ & $\begin{array}{l}\text { Inverse credibility } \\
\beta^{-1}(m)\end{array}$ & $\begin{array}{l}\beta^{-1}(m) \text { With } \\
\mathrm{m}=0.8\end{array}$ \\
\hline$(1,2)$ & $(2,4,7)$ & {$[2+4 \mathrm{~m}, 1+6 \mathrm{~m}]$} & {$[5.2,5.8]$} \\
\hline$(2,3)$ & $(3,4,5)$ & {$[3+2 \mathrm{~m}, 3+2 \mathrm{~m}]$} & {$[4.6,4.6]$} \\
\hline$(3,4)$ & $(3,4,6)$ & {$[3+2 \mathrm{~m}, 2+4 \mathrm{~m}]$} & {$[4.6,5.2]$} \\
\hline$(4,7)$ & $(2,3,5)$ & {$[2+2 \mathrm{~m}, 1+4 \mathrm{~m}]$} & {$[3.6,4.2]$} \\
\hline$(6,7)$ & $(2,4,6)$ & {$[2+2 \mathrm{~m}, 1+4 \mathrm{~m}]$} & {$[3.6,4.2]$} \\
\hline$(5,6)$ & $(2,3,4)$ & {$[2+2 \mathrm{~m}, 2+2 \mathrm{~m}]$} & {$[3.6,3.6]$} \\
\hline$(5,8)$ & $(2,3,5)$ & {$[2+2 \mathrm{~m}, 1+4 \mathrm{~m}]$} & {$[3.6,4.2]$} \\
\hline$(8,9)$ & $(3,4,6)$ & {$[3+2 \mathrm{~m}, 2+4 \mathrm{~m}]$} & {$[4.6,5.2]$} \\
\hline$(9,11)$ & $(4,5,7)$ & {$[4+2 \mathrm{~m}, 3+4 \mathrm{~m}]$} & {$[5.6,6.2]$} \\
\hline$(10,11$ & $(2,3,5)$ & {$[2+2 \mathrm{~m}, 1+4 \mathrm{~m}]$} & {$[3.6,4.2]$} \\
\hline \multicolumn{2}{|l|}{ Total weight } & {$[25+22 \mathrm{~m}, 17+38$} & {$[42.6,47.4]$} \\
\hline
\end{tabular}

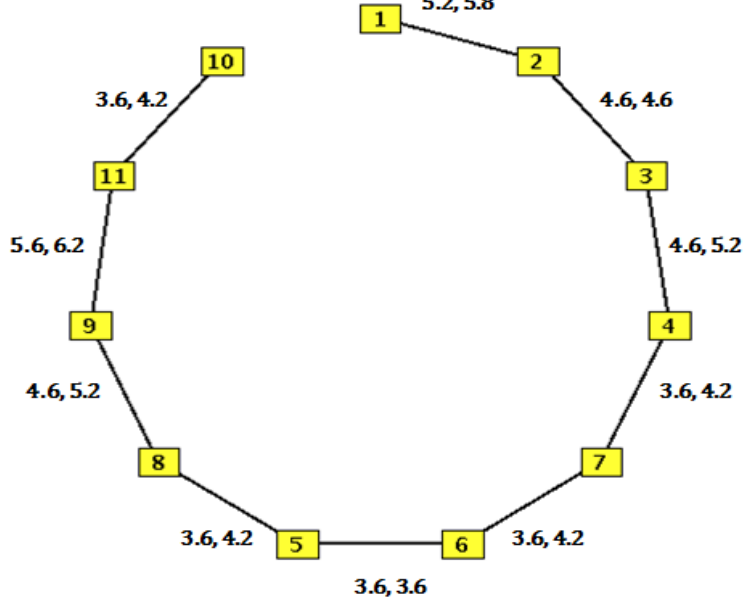

Fig.3. FMST (MANET structure)

As we know $p=$ number of nodes in the multicast tree and $n_{S}=$ no of nodes in the minimum spanning tree. According to equation (18), (26), (27) we generate Table 3.

Here Table 3 shows a brief comparative study of following areas.

1. Edge weight of pFMMST and FMST.

2. The standard deviation of edge weight of pFMMST and FMST.

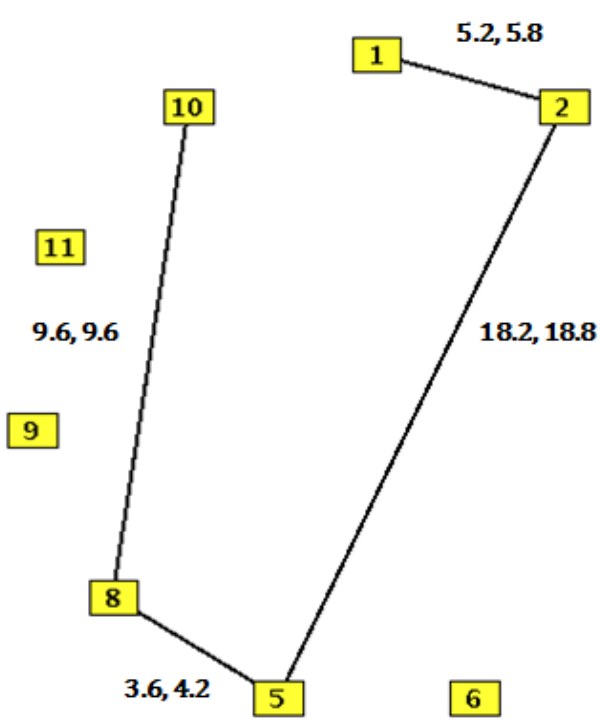

Fig.4. $(\mathrm{p}=5,1-10)$ pFMMST $($ cost $=[36.6,38.4])$

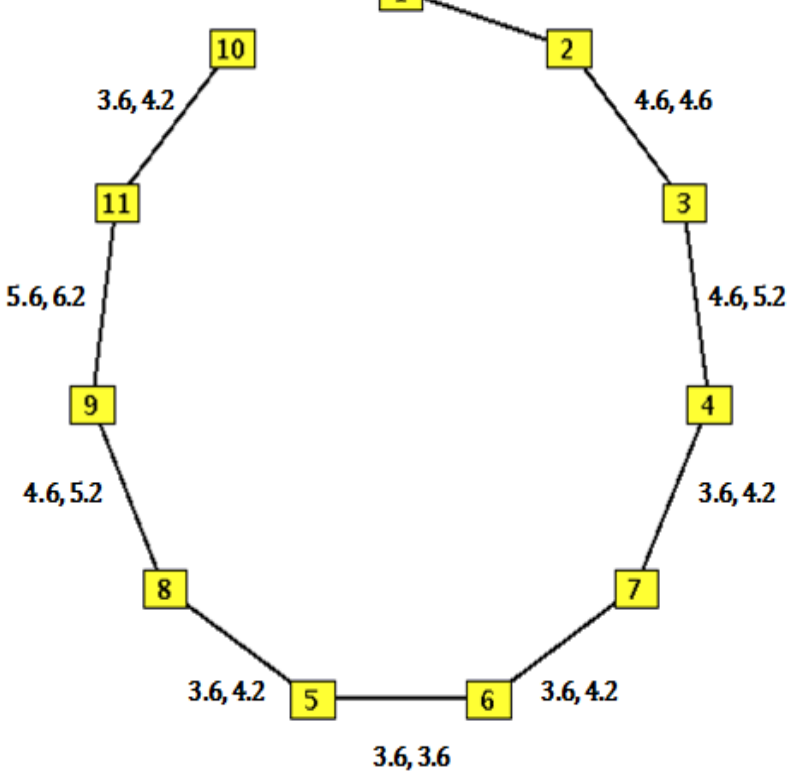

Fig.5. Using $(\mathrm{n}=11,1-10)$ FMST $(\cos t=[42.6,47.4])$

Table 3. Comparative Study of Route Cost of pFMMST and FMST

\begin{tabular}{|l|c|l|l|l|l|}
\hline $\begin{array}{l}\text { Edge } \\
\left(v_{i}, v_{j}\right)\end{array}$ & $\boldsymbol{p} \leq \boldsymbol{n}$ & $\begin{array}{l}\text { Edge cost } \\
\text { for } \\
\text { Interval } \\
\text { based value } \\
\text { pFMMST }\end{array}$ & $\begin{array}{l}\text { Edge cost for } \\
\text { Interval } \\
\text { based value } \\
\text { FMST }\end{array}$ & $\begin{array}{l}\text { Sd of } \\
\text { PFMMST }\end{array}$ & $\begin{array}{l}\text { Sd in } \\
\text { FMST }\end{array}$ \\
\hline$(1,5)$ & $3 \leq 7$ & {$[23.4,24.6]$} & {$[25.2,27.6]$} & 0.6 & 1.2 \\
\hline$(1,7)$ & $5 \leq 5$ & {$[18.0,19.6]$} & {$[18.0,19.6]$} & 0.8 & 0.8 \\
\hline$(1,8)$ & $5 \leq 8$ & {$[27.0,28.8]$} & {$[28.5,31.8]$} & 0.9 & 1.65 \\
\hline$(1,10)$ & $5 \leq 11$ & {$[36.6,38.4]$} & {$[42.6,47.4]$} & 0.9 & 2.4 \\
\hline$(1,9)$ & $6 \leq 9$ & {$[31.6,33.2]$} & {$[33.4,37.0]$} & 0.8 & 1.8 \\
\hline$(2,6)$ & $3 \leq 5$ & {$[15.8,16.4]$} & {$[16.4,19.2]$} & 0.3 & 1.4 \\
\hline$(7,11)$ & $3 \leq 5$ & {$[19.2,19.8]$} & {$[21.0,23.4]$} & 0.3 & 1.2 \\
\hline$(5,11)$ & $5 \leq 5$ & {$[13.8,15.6]$} & {$[13.8,15.6]$} & 0.9 & 0.9 \\
\hline$(4,9)$ & $3 \leq 6$ & {$[17.2,17.8]$} & {$[19.0,21.4]$} & 0.3 & 1.2 \\
\hline$(3,10)$ & $5 \leq 9$ & {$[28,29.2]$} & {$[32.8,37.0]$} & 0.6 & 2.1 \\
\hline$(6,11)$ & $5 \leq 5$ & {$[17.4,19.2]$} & {$[17.4,19.2]$} & 0.9 & 0.9 \\
\hline$(10,7)$ & $5 \leq 7$ & {$[20.4,21.6]$} & {$[24.0,27.6]$} & 0.6 & 1.8 \\
\hline
\end{tabular}


Table 4. Residual Energy of Nodes in MANET

\begin{tabular}{|l|l|l|l|}
\hline $\begin{array}{l}\text { Edge } \\
\left(v_{i}, v_{j}\right)\end{array}$ & $\begin{array}{l}\text { Inverse } \\
\text { credibility } \\
m=0.8\end{array}$ & $\begin{array}{l}\text { Energy transmit } \\
E_{T}\left(v_{i} \leftrightarrow v_{j}\right) \\
\text { nano Joule }\end{array}$ & $\begin{array}{l}\text { Energy receive } \\
T_{R}\left(v_{i} \leftrightarrow v_{j}\right) \\
\text { nano Joule }\end{array}$ \\
\hline$(1,2)$ & {$[5.2,5.8]$} & {$[421.632,426.912]$} & {$[400,400]$} \\
\hline$(2,3)$ & {$[4.6,4.6]$} & {$[416.928,416.928]$} & {$[400,400]$} \\
\hline$(3,4)$ & {$[4.6,5.2]$} & {$[416.928,421.632]$} & {$[400,400]$} \\
\hline$(4,7)$ & {$[3.6,4.2]$} & {$[410.368,414.112]$} & {$[400,400]$} \\
\hline$(6,7)$ & {$[3.6,4.2]$} & {$[410.368,414.112]$} & {$[400,400]$} \\
\hline$(5,6)$ & {$[3.6,3.6]$} & {$[410.368,410.386]$} & {$[400,400]$} \\
\hline$(5,8)$ & {$[3.6,4.2]$} & {$[410.368,414.112]$} & {$[400,400]$} \\
\hline$(8,9)$ & {$[4.6,5.2]$} & {$[416.928,421.632]$} & {$[400,400]$} \\
\hline$(9,11)$ & {$[5.6,6.2]$} & {$[425.088,430.752]$} & {$[400,400]$} \\
\hline$(10,11)$ & {$[3.6,4.2]$} & {$[410.368,414.112]$} & {$[400,400]$} \\
\hline$(8,10)$ & {$[9.6,9.6]$} & {$[473.728,473.728]$} & {$[400,400]$} \\
\hline$(6,8)$ & {$[8.2,8.8]$} & {$[453.792,461.952]$} & {$[400,400]$} \\
\hline$(5,10)$ & {$[18.8,18.2]$} & {$[682.752,664.992]$} & {$[400,400]$} \\
\hline$(2,5)$ & {$[18.2,18.8]$} & {$[664.992,682.752]$} & {$[400,400]$} \\
\hline$(7,9)$ & {$[13.6,13.6]$} & {$[547.986,547.986]$} & {$[400,400]$} \\
\hline$(3,6)$ & {$[11.2,11.8]$} & {$[500.352,511.392]$} & {$[400,400]$} \\
\hline$(1,4)$ & {$[14.8,15.4]$} & {$[575.232,589.728]$} & {$[400,400]$} \\
\hline$(1,3)$ & {$[10.8,10.2]$} & {$[493.312,483.232]$} & {$[400,400]$} \\
\hline
\end{tabular}

Table 5. Comparative Study of Residual Energy of pFMMST and FMST

\begin{tabular}{|l|l|l|l|l|l|}
\hline $\begin{array}{l}\text { Edge } \\
\left(v_{i}, v_{j}\right)\end{array}$ & $\boldsymbol{p} \leq \boldsymbol{n}$ & $\begin{array}{l}\text { Residual energy } \\
\text { Interval basedvalue } \\
\text { pFMMST }\end{array}$ & $\begin{array}{l}\text { Residual energy } \\
\text { Interval based value } \\
\text { FMST }\end{array}$ & $\begin{array}{l}\text { SD in } \\
\text { pFMMST }\end{array}$ & $\begin{array}{l}\text { SD in } \\
\text { FMST }\end{array}$ \\
\hline$(1,5)$ & $3 \leq 7$ & {$[1886.624,1909.664]$} & {$[4886.592,4904.082]$} & 11.52 & 8.745 \\
\hline$(1,7)$ & $5 \leq 5$ & {$[3265.856,3279.584]$} & {$[3265.856,3279.584]$} & 6.864 & 6.864 \\
\hline$(1,8)$ & $5 \leq 8$ & {$[2696.992,2723.776]$} & {$[5696.96,5718.176]$} & 13.392 & 10.608 \\
\hline$(1,10)$ & $5 \leq 11$ & {$[3570.72,3597.504]$} & {$[8201.44,8231.488]$} & 13.392 & 15.024 \\
\hline$(1,9)$ & $6 \leq 9$ & {$[4213.842,4227.57]$} & {$[6513.888,6539.808]$} & 6.864 & 12.96 \\
\hline$(2,6)$ & $3 \leq 5$ & {$[1717.28,1728.32]$} & {$[3254.592,3266.784]$} & 5.52 & 6.096 \\
\hline$(7,11)$ & $3 \leq 5$ & {$[1773.074,1778.738]$} & {$[4073.12,4090.712]$} & 2.832 & 8.796 \\
\hline$(5,11)$ & $5 \leq 5$ & {$[2452.384,2466.496]$} & {$[2452.384,2466.496]$} & 7.056 & 7.056 \\
\hline$(4,9)$ & $3 \leq 6$ & {$[1758.354,1762.098]$} & {$[4058.4,4074.336]$} & 1.872 & 7.968 \\
\hline$(3,10)$ & $5 \leq 9$ & {$[3394.816,3409.6]$} & {$[6510.784,6540.85]$} & 7.392 & 15.033 \\
\hline$(6,11)$ & $5 \leq 5$ & {$[3262.752,3276.864]$} & {$[3262.752,3276.864]$} & 7.056 & 7.056 \\
\hline$(10,7)$ & $5 \leq 7$ & {$[3304.832,3312.32]$} & {$[4883.488,4904.824]$} & 3.744 & 10.668 \\
\hline & & & & & \\
\hline
\end{tabular}

\section{A. Comparison of edge cost between pFMMST and} FMST

As we know for $n$ nodes MANET, total $2^{n}-(1+n+$ $\mathrm{n}_{\mathrm{C}_{2}}$ ) number of $\mathrm{p}$ node multicast groups can be created, where $p \geq 3$.According to Fig. 4 and Fig. 5, it is observed that for transferring the packet from node 1 to 10 using FMST , the overall interval based path cost is [42.6, 47.4], where for pFMMST, it will be [36.6, 38.4].

Here we can analyze the route cost more sensibly for both the cases with upper and lower limit interval based format, which signifies the variation of cost within a range due to the effect of real life uncertainty.

In case of pFMMST, packet transferring path is $v_{1} \rightarrow v_{2} \rightarrow v_{5} \rightarrow v_{8} \rightarrow v_{10}$

Using FMST, to reach same destination from same source, packet transferring path is $v_{1} \rightarrow v_{2} \rightarrow v_{3} \rightarrow v_{4} \rightarrow$ $v_{7} \rightarrow v_{6} \rightarrow v_{5} \rightarrow v_{8} \rightarrow v_{9} \rightarrow v_{11} \rightarrow v_{10}$

Involvement of a large number of nodes has the maximum possibility for data loss in MANET. Because due to increasing the node numbers, the possibility of path cost, the risk of environmental constrain, topological changes and noise inclusion are increased.

Here for FMST from the route cost [42.6, 47.4], the standard deviation of upper and lower limit value is 2.4(using equation 25).

In pFMMST for route cost $[36.6,38.4]$, the standard deviation of upper and lower limit value is 0.9(using equation 24).

According to Table3 and Fig.8, it is clear, due to atmospheric change and physical constrains, the variation of route cost at the time of data transmission in pFMMST is less or equal to FMST. So, pFMMST has less possibility for error occurrence in route cost as compare to FMST.

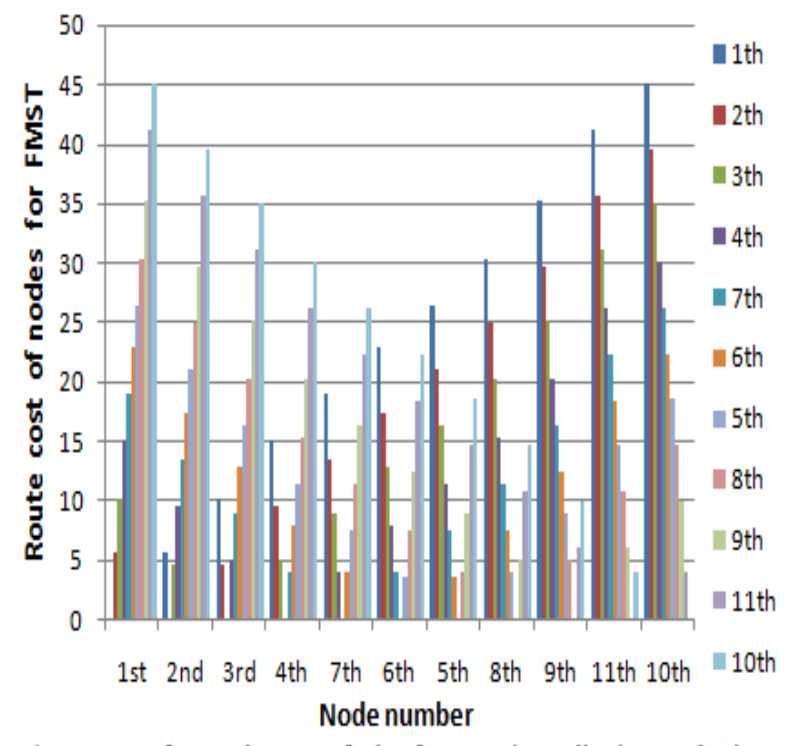

(Route cost for packet transfering from each to all other nodes)

Fig.6. Packet Transfer Path Cost in FMST in MANET

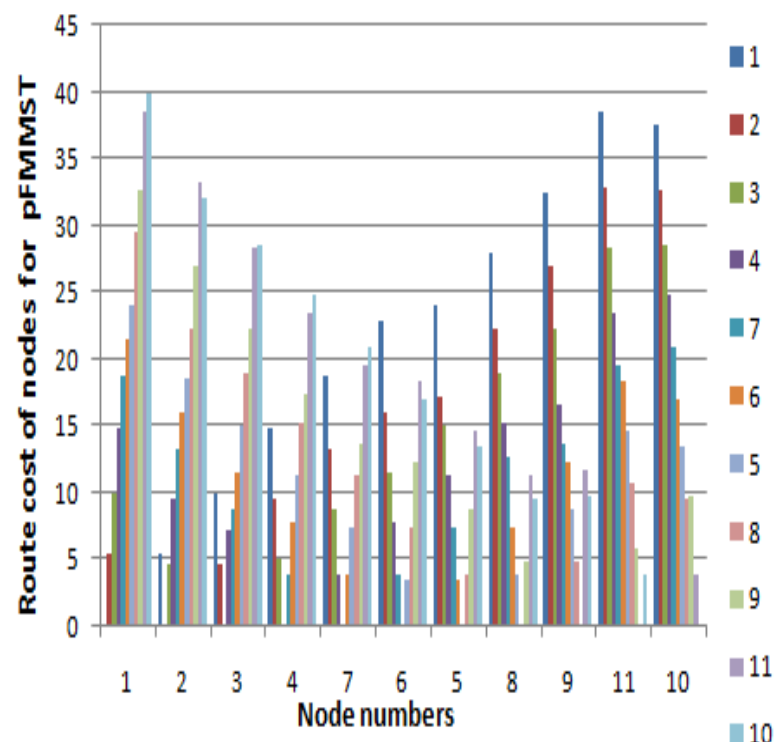

(Route cost for packet transfering from each to all other nodes)

Fig.7. Packet Transfer Path Cost in pFMMST in MANET 


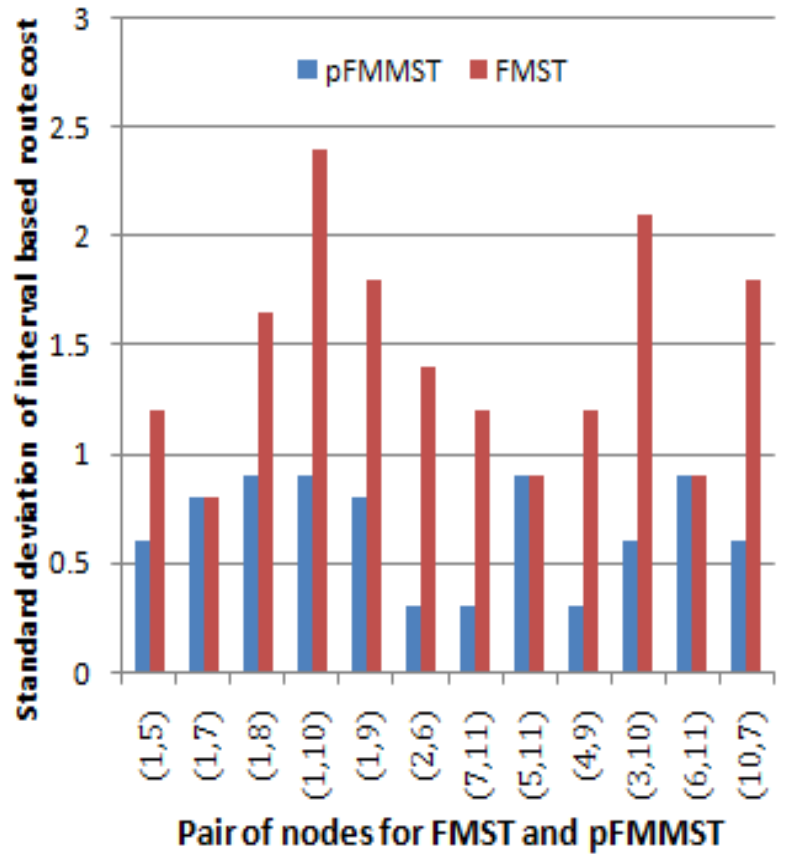

Fig.8. Edge Cost Standard Deviation of FMST and pFMMST

So, here interval based route costs in fuzzy upper and lower limit format practically justifies that pFMMST is more improved minimum spanning tree method with less data loss to transfer the data packets in an uncertain environment for MANET.

B. Comparison of residual energy between pFMMST and FMST

For FMST, according to equation (23) and Fig.5,

$$
n_{S}=11
$$

Where $i=1,2,3,4,7,6,5,8,9,11,10$ and $m=0.8$

$$
\sum_{\mathrm{i}=1}^{\mathrm{n}_{\mathrm{S}}} \widetilde{\mathrm{E}}_{\mathrm{R}}^{\mathrm{i}}=[8201.44,8231.488]
$$

For pFMMST, according to equation (24) and Fig.4, $p=5$

Where $l=1,2,5,8,10$ and $\mathrm{m}=0.8$

$$
\sum_{l=1}^{\mathrm{p}} \widetilde{\mathrm{E}}_{\mathrm{R}}^{\mathrm{i}}=[3570.72,3597.504]
$$

So, here it is shown that, for transferring packets from node 1 to node 10 , total residual energy utilization at pFMMST is smaller than energy utilization at FMST.

Considering $(1,10)$ node pair, for FMST from the energy utilization [8201.44, 8231.488], the standard deviation of upper and lower limit value is 15.023 (using equation 30)

In pFMMST for energy utilization [3570.72, 3597.504], the standard deviation of upper and lower limit value is 13.39(using equation 29).

According to Table5 and Fig.11, it shows that for most of the pair of nodes, pFMMST has less possibility for error occurrence than FMST in energy utilization.

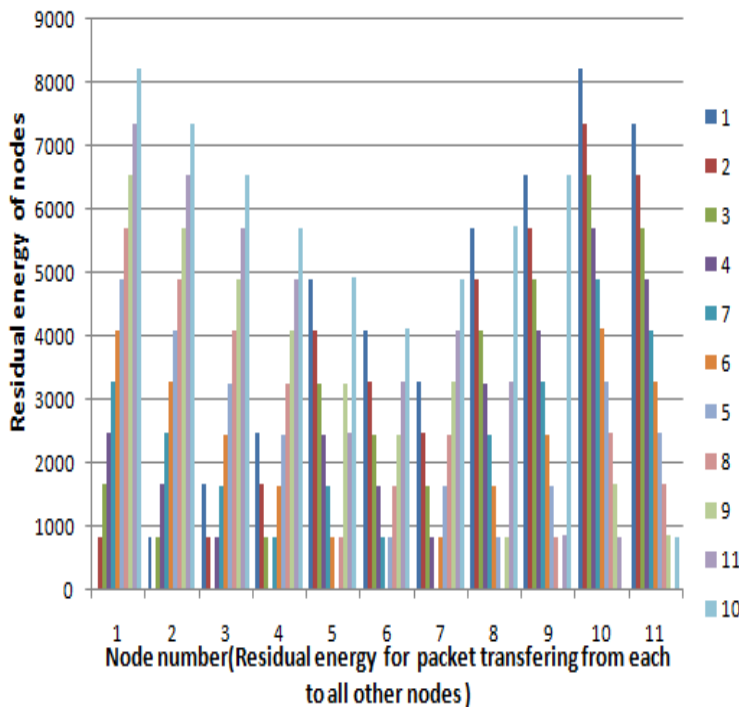

Fig.9. Fuzzy Residual Energy for FMST in MANET

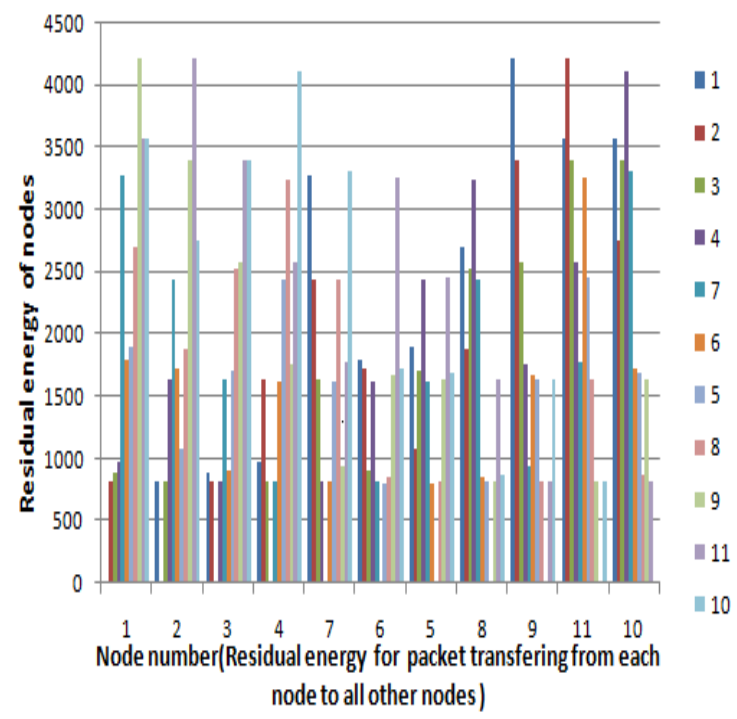

Fig.10. Fuzzy Residual Energy for pFMMST in MANET

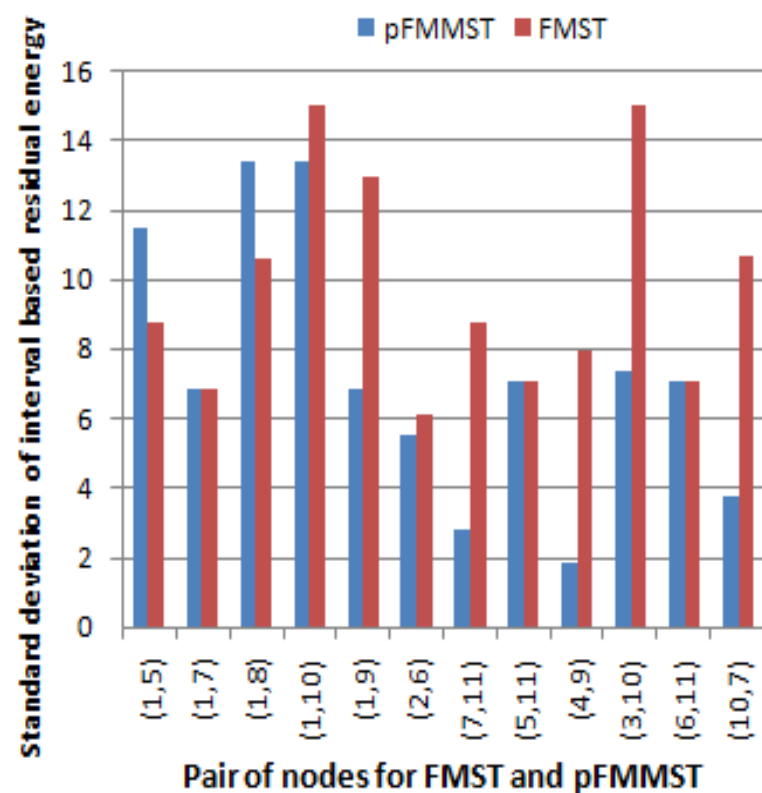

Fig.11. Residual Energy Standard Deviation of FMST and pFMMST 


\section{CONCLUSIONS}

Here we try to implement m-minimum fuzzy triangular number in interval based format, using inverse credibility distribution to represent the minimum spanning tree and pFMMST of MANET. Where we compare the fuzzy path cost, total fuzzy residual energy and interval-based data deviation error for transferring the packets through both the acyclic tree structure of MANET and generate a conclusive decision. Here the reason for applying fuzzy concept is to attach the real-life constrains like rapid topological changes, insertion of noise or climatic variation with the architecture and achieve the most optimized result in MANET. Using the interval based fuzzy concept, it makes easier to generate approximated values, in place of contradictory point estimated results. Here in MANET structure we only consider the digital devices as nodes, but we did not consider separate sensor device as an active node. In future we can try to apply wireless sensor architecture with MANET in a fuzzy environment, using the artificial neural network for training the network path to generate more optimized results.

\section{REFERENCES}

[1] Chen, Y.S., Kao, T.C., Sheu, J.P. and Chiang, C.Y., A mobile scaffolding - aid - based bird watching learning system, Wireless and mobile technology in Education, 2002. Proceedings, IEEE International Workshop (IEEE WMTE 2002 ), Teleborg Campus, Sweden, August 29-30, p. $15-22$.

[2] King, C.T., Lin, M.P. and Sun, M.T., Neighbor - aided multicast protocol for streaming transmission on MANETs, Proc. of International Conference on Grid and Pervasive Computing(GPC2006), May 2006.

[3] Ko, Y., Vaidya, N., Location - aided Routing (LAR) in mobile ad- hoc networks, Proceedings of the ACM /IEEE International Conference on Mobile Computing and Networking (MOBICOM), 25- 30 October, 1998, p.66-75.

[4] Jttner, A., Magi, D.,Tree based broadcast in ad- hoc networks, MONET Special Issue on WLAN Optimization at the MAC and Network Levels.

[5] Penttinen, A., Minimum cost multicast trees in ad hoc networks, Communications, 2006. ICC '06. IEEE International Conference, June, p.3676 - 3681.

[6] B.R., Reddy, A.K., L.C., Hiremath, P.S. and Sheshadri, R. $\mathrm{K}$ - nodes multicasting minimum cost spanning trees in wireless mobile ad-hoc network (MANET),International Journal of Computer Applications 1(4), February, p. 0975 $-8887$.

[7] Gupta, S., Bharti, P. K., Choudhary, V.,Fuzzy Logic Based Routing Algorithm for Mobile Ad Hoc network, In Lecture Notes in High Performance, Architecture and grid computing Springer-2011, p.574-579.

[8] Chen, Y.S., Lee, S. and Lin, T.H., PCAR: A power-aware chessboard-based adaptive routing protocol for wireless sensor networks , Journal of Internet Technology, Special Issue on Wireless AdHoc Network and sensor April 2005. (EI).

[9] Yu,H.,Chen,G.,Zhao,S,C.Y and Chin, Y.T., An efficient wireless recharging mechanism for achieveing perpetual lifetime of wireless sensor network, Sensor 2017,17(1).

[10] Zhou, J., Chen, L., Wang, K. and Yang, F., Fuzzy $\alpha-$ minimum spanning tree problem: definition and solutions,
International Journal of General Systems, 45(3), p.311335.

[11] Itoh, T. and Ishii, H., An approach based on necessity measure to the fuzzy tree Problems, Journal of the Operations Research, 39(2), June, p.247-257.

[12] Chang, P. T. and Lee, E., Fuzzy decision networks and deconvolution, Computers \& Mathematics with Applications, 37(11), p.53-63.

[13] Almeida, T.A., Prado, F. M. S., Souza, V. N., Yamakami A. and Takahashi, M. T., A genetic algorithm to solve Minimum spanning tree problem with fuzzy parameters using possibility measure, Fuzzy Information Processing Society,2005.NAFIPS 2005 -2005 Annual Meeting of the North American Fuzzy Information Processing society.

[14] Deng, Y., Chen, Y., Zhang, Y. and Mahadevan, S., Fuzzy Dijkstra algorithm for shortest path problem under uncertain environment, Applied Soft Computing, November, p.1231-1237.

[15] Xu, M., Liu, Y., Huang, Q., Zhang, Y. and Luan, G., An improved Dijkstra shortest path algorithm for sparse network, Applied Mathematics and Computation, 185(1), p.247-254.

[16] Lin, Y.W., Chen, Y.S. and Lee, S.L., Routing protocols In vehicular ad hoc networks: a survey and future perspectives, Journal of Information Science and Engineering, 26(3), May, p.913-932.

[17] Chuang, T.N. and Kung, J.Y., The fuzzy shortest path length and the corresponding shortest path in a network, Computers \& Operations Research, 32(6), p.1409-1428.

[18] Sadiq, R. S. and Tesfamariam, S., Developing environmental indices using fuzzy numbers ordered weighted averaging (FN-OWA) operators, Stochastic Environmental Research and Risk Assessment, 22(5), p.495-505.

[19] Deng, Y., Shi, W.K., Du, F. and Liu, Q., A new similarity measure of generalized fuzzy numbers and its application to pattern recognition, Pattern Recognition Letters, 25(8), p.875-883.

[20] Maihöfer, C., A survey of geocast routing protocols, IEEE communications Surveys \& Tutorials, 6(2), p.32-42.

[21] Gui, C. and Mohapatra, P., scalable multicasting in mobile ad hoc networks, IEEE INFOCOM 2004.

[22] B.R, A.K., Reddy, L.C., Rajan, C.C.A. and Hiremath P.S., Route failure tolerant multicast in mobile ad hoc networks using disjoint minimum spanning trees, The second IEEE ICCSIT 2009, August 8 - 11, Beijing,China.

[23] Haider, T. and Yusuf, M., A Fuzzy Approach to Energy Optimized Routing for Wireless Sensor Networks, The International Arab Journal of Information Technology, 6(2),April 2009, p.179-185.

[24] Madhurya, M., Krishna, B.A. and Subhashini, T., Implementation of Enhanced Security Algorithms in Mobile Ad hoc Networks, IJCNIS, 6(2), p.30-37, 2014. DOI: $10.5815 /$ ijcnis.2014.02.05

[25] Xin ZHANG, Ying ZHANG, Raees ALTAF, Xin FENG, A Multi-agent System-based Method of Detecting DDoS Attacks, International Journal of Computer Network and Information Security (IJCNIS), 2018 10(2), p.53-64, DOI: 10.5815/ijcnis.2018.02.07.

[26] Sathiamoorthy,J.and Ramakrishnan,B.,CEAACK - A Reduced Acknowledgment for Better Data Transmission for MANETs, International Journal of Computer Network and Information Security (IJCNIS), 2016, 8(2), p.64-71, DOI: 10.5815/ijcnis.2016.02.08.

[27] Khare, A.K., Rana, J.L. and Jain, R. C., Detection of, Wormhole Blackhole and DDOS Attack in MANET using Trust Estimation under Fuzzy Logic Methodology, 
International Journal of Computer Network and Information Security (IJCNIS), 2017,9(7), p.29-35, DOI: 10.5815/ijcnis.2017.07.04

[28] Sharma, V.K., Verma, L.P. and Kumar, M., A FuzzyBased Adaptive Energy Efficient Load Distribution Scheme in Ad-hoc Networks, International Journal of Intelligent Systems and Applications (IJISA), $2018,10(2)$, p.72-84, 2018. DOI: 10.5815/ijisa.2018.02.07.

[29] Sivaraj, C., Alphonse, P. J. A. and Janakiraman, T. N., Energy-efficient and load distributed clustering algorithm for dense wireless sensor networks, International Journal of Intelligent Systems and Applications (IJISA), May 2017. 9(5), pp. 34-42.

[30] Das,I., Lobiyal, D.K. and Katti, C.P., An Analysis of Link Disjoint and Node Disjoint Multipath Routing for Mobile Ad Hoc Network, International Journal of Computer Network and Information Security (IJCNIS), 2016. 8(3), p.52-57. DOI: 10.5815/ijcnis.2016.03.07.

[31] Periyasamy, P. and Karthikeyan, E., Performance Comparison and Evaluation of Different Multipath Routing Protocols Based on Various Scenario and Traffic Patterns for Mobile AD Hoc Networks, International Journal of Computer Network and Information Security 2013,5(1), p.24-32.DOI: 10.5815/ijcnis.2013.01.03.

\section{Authors' Profiles}

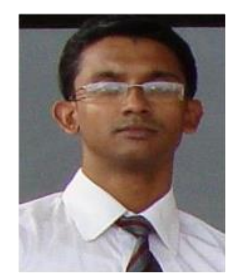

Soham Bandyopadhyay is a Lecturer in the Dept. of Computer Science and Technology at Dr.B.C. Roy Polytechnic, Durgapur, India. $\mathrm{He}$ received B.TECH in Computer science and Engg. from West Bengal University of Technology, MBAfrom SMU, M.TECH from National Institute of Technology, Durgapur India.His research interests are in the areas of wireless ad-hoc network systems, soft computing, fuzzy logic.

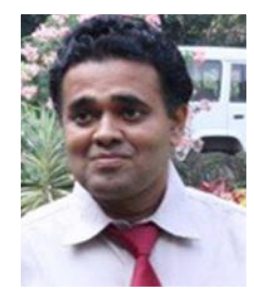

Sunil Karforma is a Professor in the Dept.of Computer Science at The University of Burdwan, West Bengal, India. He received B.TECH and M.TECH in Computer Science and Engineering from Jadavpur University, West Bengal, India. He received his Ph.D from The University of Burdwan, West Bengal, India in Computer Science. His research interests are in the areas of wireless network systems, e-commerce, network security, soft computing.

How to cite this paper: Soham Bandyopadhyay, Sunil Karforma,"Improving the Performance of Fuzzy Minimum Spanning Tree based Routing Process through P-Node Fuzzy Multicasting Approach in MANET", International Journal of Computer Network and Information Security(IJCNIS), Vol.10, No.6, pp.16-26, 2018.DOI: 10.5815/ijcnis.2018.06.02 